\section{Suicide and the use of antidepressants}

\section{Drug treatment of depression is inadequate}

EDrToR,-Göran Isacsson and colleagues suggest that therapeutic failure of antidepressant drugs may be a greater problem in people who commit suicide than toxicity in overdose as their results indicated no advantage of the newer, less toxic drugs; furthermore, their results confirmed that only a small minority of people who commit suicide have received antidepressant treatment before death despite the high prevalence of depression in the population. ${ }^{1}$ The notable problems in their otherwise impressive database were, however, that they had neither diagnostic information nor knowledge of the dosage used in the cases studied. As our work may contribute to these questions, ${ }^{2}$ we wish to confirm and extend their findings.

In the national suicide prevention project in Finland all suicides $(n=1397)$ in Finland committed between 1 April 1987 and 31 March 1988 were comprehensively examined by the psychological necropsy method. Mental disorders were evaluated retrospectively, according to the criteria in the Diagnostic and Statistical Manual of Mental, Disorders, third edition, revised, in a diagnostic study of a random sample of 229 suicides. ${ }^{3}$ In this study 71 of the 229 people who had committed suicide were estimated to have had current unipolar major depression.

Further examination of these 71 people showed that only 22 out of $66(33 \%)$ had received antidepressant treatment (the information concerning possible antidepressant treatment was insufficient in four cases and conflicting in one) ${ }^{2}-a$ finding similar to the proportion $(30 \%)$ reported by Barraclough et al in West Sussex. ${ }^{4}$ Most notably, only two people had received antidepressants in adequate doses (doxepin $250 \mathrm{mg} / \mathrm{day}$ and mianserin $60 \mathrm{mg} /$ day). None of the others had received more than an equivalent of $100 \mathrm{mg}$ of a tricyclic antidepressant daily. Thus only $3 \% \quad(2 / 66)$ of people with current major depression who committed suicide were receiving adequate antidepressant treatment. ${ }^{2}$

In our study population, which effectively represented all suicides among people with major depression in Finland, only 8\% (6/71) committed suicide by taking an overdose of antidepressant (three cases of intoxication with other psychopharmacological agents were also found). ${ }^{2}$ Most of the people with major depression who committed suicide, especially men, used violent methods, even if they were receiving drug treatment. A finding with implications for future studies using prescription databases was that in four of the nine cases of suicide due to intoxication with psychopharmacological agents the drug taken in overdose was not currently being used for treatment. ${ }^{2}$ Thus

Priority will be given to letters that are less than 400 words long and are typed with double spacing. All authors should sign the letter. Please enclose a stamped addressed envelope for acknowledgment. depressed people may save drugs from earlier treatment periods and use them in a lethal overdose. A fatal toxicity index reflects the risk of fatal overdose per prescriptions in the population, but this may be different from the risk per current period of treatment with the particular drug.

ERKKI ISOMETSÄ MARKUS HENRIKSSON MARTTI HEIKKINEN HILLEVO ARO

Department of Mental Health, JOUKO LÖNNQVIST

National Public Health Institute, SF-00300 Helsinki, Finland

1 Isacsson G, Holmgren P, Wasserman D, Bergman U. Use of antidepressants among people committing suicide in Sweden. BMF 1994:308:506-9 people commiti

2 Isometsă ET, Henriksson MM, Aro HM, Heikkinen ME, Kuoppasalmi KI, Lonnqvist JK. Suicide in major depression. Am ₹ Psychiatry 1994;151:530-6.

3 Henriksson MM, Aro HM, Martunnen MJ, Heikkinen ME Isometsă ET, Kuoppasalmi KI, et al. Mental disorders and comorbidity in suicide. Am F Psychiatry 1993;150:935-40.

4 Barraclough BM, Bunch J, Nelson B, Sainsbury P. A hundred cases of suicide: clinical aspects. $B r \mathcal{F}$ Psychiatry 1974;125: 355-73.

\section{Nearly a third of deaths related to poisoning}

EDrToR,-In their study examining the detection of antidepressants at postmortem examination Göran Isacsson and colleagues concluded that, because few suicides are associated with toxic concentrations of antidepressants and the newer, less toxic antidepressants seem to be overrepresented in relation to their estimated use, therapeutic failure may be more important than toxicity. ${ }^{1}$ Although the use of antidepressants was standardised for age, sex, and geographical area when rates of detection in cases of suicide were compared, two further potential confounding factors were not addressed. Firstly, in cases in which clinicians were concerned about the possibility of suicide they probably prescribed less toxic drugs. Secondly, patients who had longstanding depression resistant to treatment had probably been prescribed newly developed antidepressants, and a higher rate of suicide would be expected in this group. Both of these factors would result in an overrepresentation of the less toxic drugs mianserin and moclobemide in cases of suicide.

The data presented show that 190 of the 585 patients who were taking antidepressants at the time of death had a toxic concentration of these drugs. This suggests that up to $30 \%$ of deaths in these patients had been caused by overdose of antidepressant. Contrary to the authors' conclusion, toxicity may be of the utmost importance in patients who are taking antidepressants.

The study was useful in emphasising the apparent underuse of antidepressant drugs by patients who commit suicide. But it is not possible to conclude that therapeutic failure is more important than toxicity; indeed, toxicity may be an important cause of death in patients prescribed antidepressants.

ANDREW OWEN Queen Elizabeth Psychiatric Hospital Senior house officer in psychiatry Birmingham B15 2QZ

1 Isacsson G, Holmgren P, Wasserman D, Bergman U. Use of antidepressants among people committing suicide in Sweden. BMF 1994;308:506-9. (19 February.)

\section{Patients at greatest risk given newer drugs}

EDrroR,-Göran Isacsson and colleagues report that most depressed patients who commit suicide are not taking antidepressants immediately before their death and that therapeutic failure may be a greater problem with antidepressants than toxicity. ${ }^{1}$ I agree that the results may be explained by the authors' hypothesis that mianserin and moclobemide are less effective than tricyclic antidepressants. I wish, however, to propose an alternative explanation-namely, that these newer drugs, because of their greater safety in overdose, may have been preferentially prescribed to patients judged to be at higher risk of suicide. A history of parasuicide is a known predictor of the risk of suicide in the future; when faced with a patient with such a history, practitioners may opt for a less toxic alternative to the older antidepressants. (Personal experience and discussion with colleagues suggest that this is often the case.)

The conclusion that newer, less toxic antidepressants seem more likely to result in therapeutic failure is open to misinterpretation. The new antidepressants with low toxicity that are most widely prescribed in Britain are the selective serotonin reuptake inhibitors, which were not examined in detail by this study. It would have been more accurate to restrict this statement to mianserin and moclobemide.

Department of Psychiatry,

TOM O'HARE

Rochdale Healthcare NHS Trust,

Birch Hill Hospital,

Bochdale OL12 9OB

1 Isacsson G, Holmgren P, Wasserman D, Bergman U. Use of antidepressants among people committing suicide in Sweden. BMF 1994;308:506-9. (19 February.)

\section{Depression may not precede suicide}

EDrToR,-Göran Isacsson and colleagues attempted to address an important psychopharmacological issue-namely, whether different classes of antidepressant drugs have differential effects on suicidality. ${ }^{1}$ Tricyclic drugs are toxic in overdose, ${ }^{2}$ and taking them is an effective method of suicide. Most suicides, however, are not due to overdose of antidepressants. ${ }^{3}$ It is more relevant to consider the relative potency of the antidepressant effect and the effect on suicidality when comparing tricyclic with non-tricyclic drugs. There are minimal data on which to base firm conclusions.

We wish to challenge some of the assumptions that underpin this paper. The authors' stated objective was "to analyse the outcome of depression as reflected by detection of antidepressants" in a sample of unnatural deaths. An assumption that suicide is almost invariably preceded by depression is incorrect. Recent studies estimate that between $34.6 \%{ }^{3}$ and $66 \% \%^{4}$ of suicide victims may have suffered from depression.

The proportion of people who died with evidence of antidepressant drugs in their blood is low, being $15.9 \%(542 / 3400)$ among the suicide cohort and $7.7 \%(542 / 7000)$ among the total deaths examined. Similarly, the proportion who died with toxic concentrations of antidepressant drugs is low, being $5 \cdot 6 \%(190 / 3400)$ and $2 \cdot 7 \%(190 / 7000)$ respectively. The authors concluded that these findings implied failure to detect and treat depressive illness effectively. This may be correct, but alternative explanations must be considered. 